We appreciate the response to this publication feature and welcome all contributions. Contributions may be sent to José A. Mascorro, our Technical Editor, at hise-mail address: jmascor@tulane.edu. José may also be reached at the Department of Structural and Cellular Biology, Tulane University Health Sciences Center, 1430 Tulane Ave., New Orleans, LA 70112 and Ph: (504) 584-2747 (504) 584-1687

\section{Specimen Capsules For Critical-Point Drying}

\author{
Sol Sepsenwol \\ University of Wisconsin, Stevens Point \\ ssepsenw@uwsp.edu
}

Since we do a lot of small-sample critical-point drying (CPD) for SEM, we assemble our own drying capsules which can be manufactured easily in quantity. Materials' cost at current prices is about $\$ 10$ for 50 capsules. About 25 capsules can be manufactured in an hour. The completed capsule consists of a small polypropylene chamber with fine-mesh, stainless-steel screen caps at each end that allow easy exchange of solvents. Figure 1 shows the steps of the assembly process. The base of one capsule is cut off with a razor blade, the cap of a second capsule, for a bottom

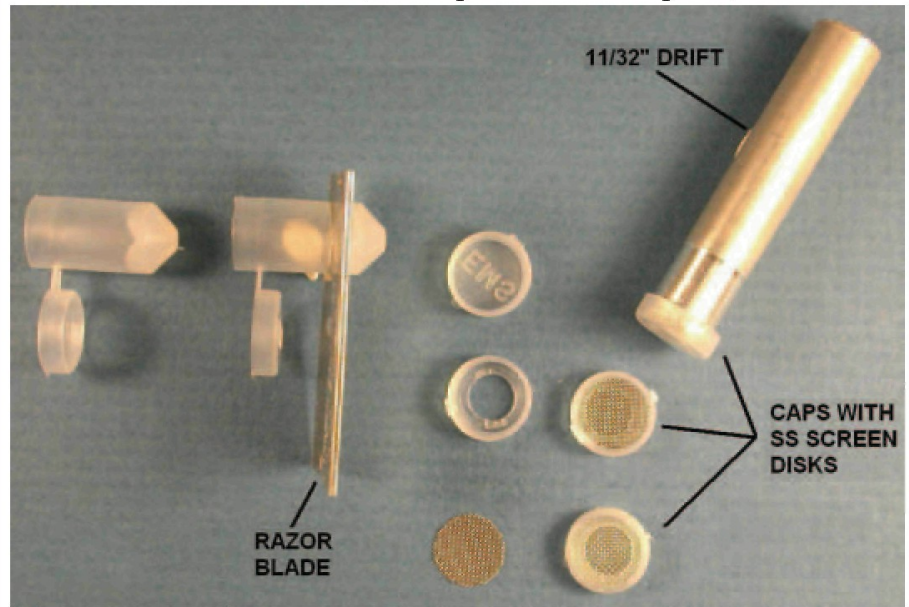

Figure 1. The completed CPD capsule. Free exchange of solvent occurs through the wire-mesh caps.

(Figure 1a). Chamber length can be 5 to $14 \mathrm{~mm}$. One-quarter-inch holes are punched through the center of each cap using a paper punch whose spring/detente has been removed to pass the caps' rim (Figure 1b). A sheet-metal shim punch is used to create $3 / 8$ " disks of 60 -mesh stainless steel wire cloth. Several hundred disks can be made from one square foot of wire cloth. Screen disks are pressed into caps with a finger, then a $3 / 8$ " sanded wood dowel or $11 / 32$ " drift is used to set the screen into each cap (Figure 1a). The wire ends embed in plastic and hold it firmly in place. Capsules are numbered with a scribe, and may be sonicated in solvent, cap closed, to clean.

In use, the attached cap is the top of the capsule. Up to 24 capsules are immersed in wells of ethanol in a 24 -well tissue-culture plate, top open. The sample(s) are transferred into the capsule by wide-bore pipette, and the caps snapped shut. Capsules can be transferred to fresh solvent in 50 - $\mathrm{ml} \mathrm{screw-top} \mathrm{T/C} \mathrm{tubes} \mathrm{until} \mathrm{ready} \mathrm{for} \mathrm{drying.} \mathrm{It} \mathrm{is} \mathrm{best} \mathrm{to} \mathrm{tap} \mathrm{the} \mathrm{tube}$ sharply to drive out air bubbles that may be trapped beneath the caps; all capsules should sink. For very small samples (pollen, etc.), two disks of lens tissue (punched from a stack of tissue with the same $3 / 8$ " punch) can be placed beneath the screen of each cap before samples are added.

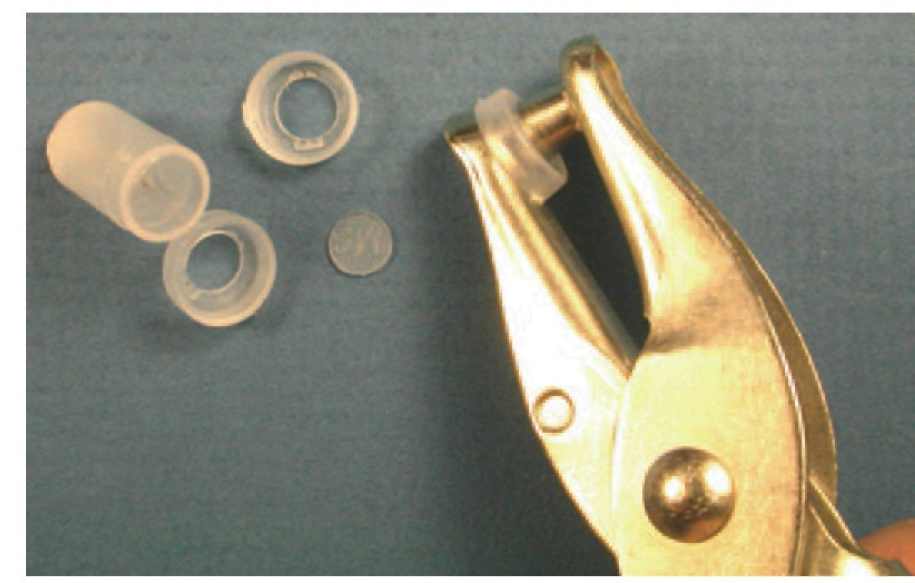

Figure 2. Chamber manufacture. (a) Preparing the capsules. Half the capsules are used for chambers and top caps; half, for bottom caps. Stainless steel disks are tamped into punched caps with a 11/32" drift. (b) Modified 1/4" hole punch is centered in top of each cap, die below.

Supplies (sources are suggestions only):

1. BEEM ${ }^{\text {ma }}$-style polypropylene embedding capsules, size 00 , with caps (Ted Pella Inc, p/n \#130, \$8/pkg 100) URL: http://www.tedpella. com/embed html/beem $1 . h t m \#$ anchor 130638

2. $3 / 8$ " shim metal punch \& die (MSC Industrial Supply, set of 9 punches, $\mathrm{p} / \mathrm{n} \# 48424501$, $\$ 85$ set of 9 punches. URL: http://wwwl. mscdirect.com/CGI/NNSRIT?PARTPG=NNLMK3\&PMPXNO=85 42610, )

3. 60-mesh stainless-steel wire cloth (MSC Industrial Supply, $\mathrm{p} / \mathrm{n}$ \#52429370, \$8/sheet, 12" x 12".) URL: http://www1.mscdirect. $\mathrm{com} / \mathrm{CGI} / \mathrm{NNSRIT}$ ?PARTPG $=$ NNLMK32\&PMPXNO $=1929022$

\section{W NBL \\ Marine Biological Laboratory $\bullet 7 \mathrm{MBL}$ Street $\bullet$ Woods Hole $\bullet$ MA $\bullet 02543$ \\ 2005 Microscopy Courses \\ Analytical \& Quantitative Light Microscopy May 5 - May 13, 2005}

Application Deadline: February 4, 2005

This comprehensive course provides an in-depth examination of the theory of image formation and the application of video methods for exploring subtle interactions between light and the specimen.

\section{Optical Microscopy \& Imaging in the Biomedical Sciences October 11 - October 20, 2005}

Application Deadline: June 20, 2005

This course will enable the participant to obtain and interpret microscope images of high quality to perform quantitative optical measurements and to produce video and digital records for documentation and analysis.

For further information and applications, visit our website:

\section{www.mbl.edu/education}

or contact: Carol Hamel, Admissions Coordinator

(508)289-7401; admissions@mbl.edu 


\section{for Specimen Preparation.}
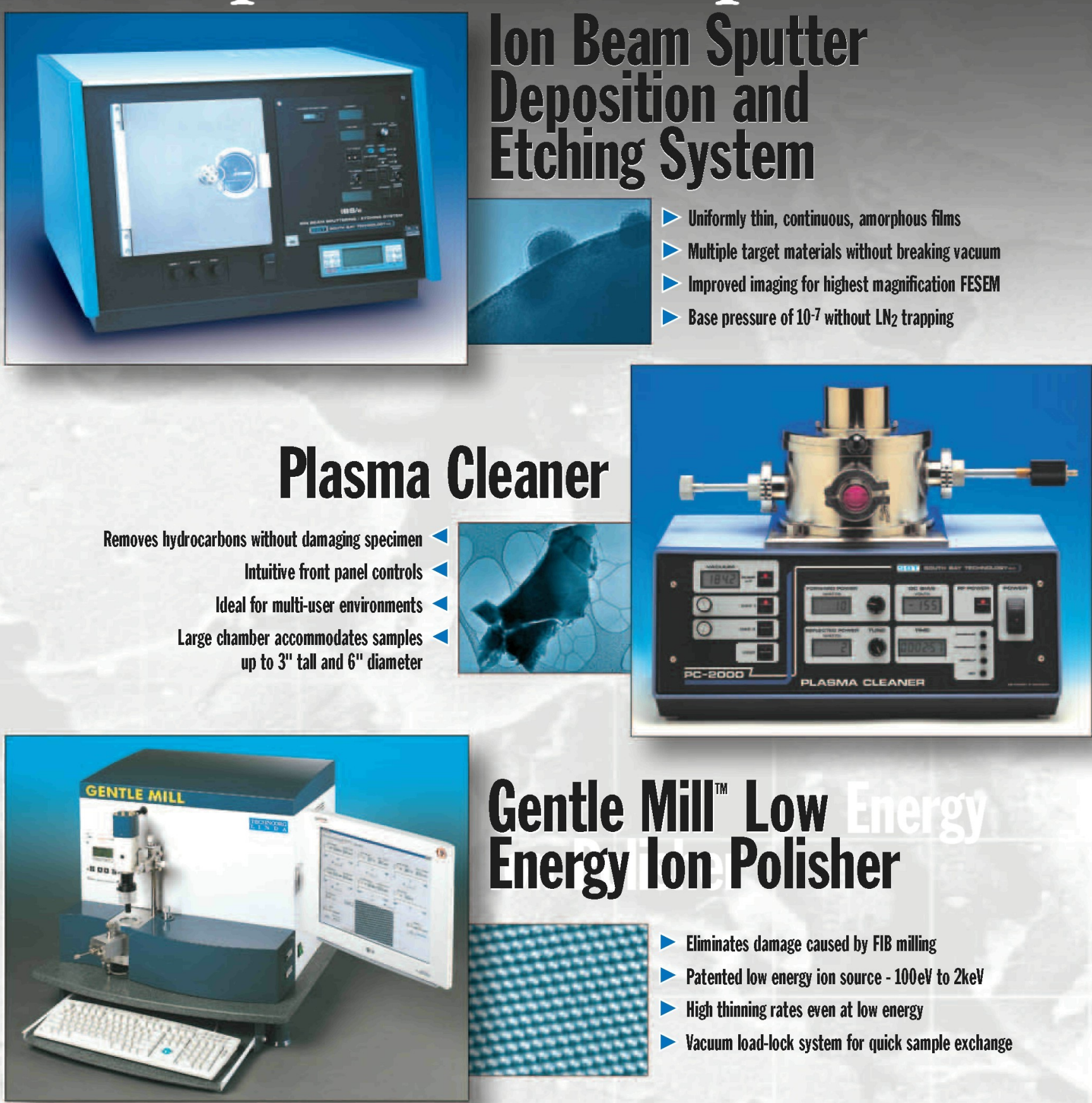

- Eliminates damage caused by FIB milling

- Patented low energy ion source - $100 \mathrm{eV}$ to $2 \mathrm{keV}$

- High thinning rates even at low energy

- Vacuum load-lock system for quick sample exchange

www.southbaytech.com

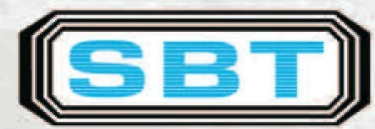

SOUTH BAY TECHNOLOCY, INE.

1120 Via Callejon | San Clemente, CA 92673 | U.S.A. | 949-492-2600 | Fax: 949-492-1499

Toll Free: 800-728-2233 | email: info@southbaytech.com | www.southbaytech.com 